\title{
Caracterização físico-química do extrato fluido e seco por nebulização de Symphytum officinale $\mathrm{L}$.
}

\author{
José Otávio Carréra Silva Júnior ${ }^{*}$, José Luiz Fernandes Vieira², Wagner Luiz Ramos \\ Barbosa $^{3}$, Newton Lindolfo Pereira ${ }^{4}$
}

\author{
${ }^{1}$ Laboratório de Farmacotécnica, Departamento de Farmácia, Universidade Federal do Pará, Campus \\ Universitário do Guamá, 66075-110, Guamá, Belém, PA, Brasil, \\ ${ }^{2}$ Laboratório de Toxicologia, Departamento de Deontologia e Medicina Legal, Universidade Federal do Pará, \\ Campus Universitário do Guamá, 66075-110, Guamá, Belém, PA, Brasil, \\ ${ }^{3}$ Laboratório de Fitoquímica, Departamento de Farmácia, Universidade Federal do Pará, Campus Universitário do \\ Guamá, 66075-110, Guamá, Belém, PA, Brasil, \\ ${ }^{4}$ Laboratório de Farmacotécnica, Departamento de Ciências Farmacêuticas, Faculdade de Ciências Farmacêuticas \\ de Ribeirão Preto, Av. do Café s/n, Monte Alegre,14040-903, Ribeirão Preto, SP, Brasil
}

\begin{abstract}
RESUMO: O artigo reporta a obtenção do extrato fluido de Symphytum officinale L., e posterior secagem por nebulização, e a caracterização físico-química por técnicas termogravimétricas, espectroscópicas e cromatográficas. O adjuvante de secagem utilizado foi hidroxietilcelulose na concentração de $1,5 \%$. Foi observado que o processo de secagem por nebulização, nas condições operacionais estabelecidas, não influenciou as características dos constituintes do extrato seco em relação ao extrato fluido pelas técnicas utilizadas.
\end{abstract}

Unitermos: Symphytum officinale, parâmetros de secagem, hidroxietilcelulose, TGA, IV, CLAE.

\begin{abstract}
Phisycal chemistry characterization of fluid and dry nebulization extract of Symphytum officinale L.” This work reports the obtaining of the Symphytum officinale L. fluid extract dried by spray-drying and its physicochemical characterization by thermogravimetric analysis, spectroscopic and chromatographic techniques. Hydroxyethylcellulose at $1,5 \%$ was used as technological adjuvant. We observed that the drying process by spray-dryer, on the established operational conditions, did not have influence in the characteristics of the dry extract constituents in relation to the fluid extract by the used techniques.
\end{abstract}

Keywords: Symphytum officinale, spray drying, hydroxyethylcellulose, TGA; IR; HPLC.

\section{INTRODUÇÃO}

O uso de plantas medicinais no Brasil vem se consolidando nos últimos tempos em especial com a promulgação da Política Nacional de Plantas Medicinais e Fitoterápicos (Brasil, 2004). Dados da Organização Mundial de Saúde (OMS) mostram que mais da metade dos habitantes da terra especialmente nos países pobres e em desenvolvimento fazem uso de ervas medicinais na busca de alívio de sintomatologia dolorosa ou desagradável, e que desse total pelo menos $30 \%$ as utilizam por indicação médica (Estrela, 1995). No mercado brasileiro de medicamentos e cosméticos, $25 \%$ dos produtos fabricados contêm princípios ativos naturais.

Symphytum officinale L. (confrei) é uma Boraginaceae de clima temperado que foi introduzido no Brasil e se adaptou facilmente às regiões de clima tropical. Ocorre entre os estados do Paraná e Amazonas, principalmente em São Paulo (Alzugaray; Alzugaray, 1988), onde, entretanto, é encontrada apenas na forma cultivada (Matos, 1994). O estudo morfoanatômico das folhas e raíz desta espécie foi descrito por Toledo et al. (2003; 2006). No extrato etanólico das folhas foram detectadas as seguintes classes de metabólitos secundários: alcalóides, flavonosídeos, esteróides e triterpenóides. Já o extrato aquoso contém: saponosídeos e taninos condensados, principalmente. Compostos fenólicos foram encontrados no rizoma além de amido e lignina (Toledo et al., 2006).

Diversas propriedades terapêuticas, tais como atividade hemostática e antiinflamatória, são atribuídas à planta toda, mas principalmente às raízes e rizomas devido à presença de taninos e mucilagens; já a alta atividade cicatrizante, é atribuída à substância alantoína, que atua como regeneradora, estimulando o crescimento de tecidos novos e sadios (Duarte, 1984; Falcão et al., 2005). Nesse sentido recomenda-se a incorporação do

ISSN 0102-695X 
extrato fluido de Symphytum em cremes evanescentes a fim de potencializar a ação umectante e emoliente de tais preparações (Soares et al., 1986). Outras propriedades terapêuticas, descritas para esta espécie são: anticoagulante (Chiryat'ey; Rusakova, 1994), bactericida, antifúngica e antihipertensiva (Sener; AttaUr, 1994). Morrison e West (1982) avaliaram o potencial hipoglicemiante de dezenas de espécies de plantas. O extrato aquoso das folhas de Symphytum officinale estava entre os menos ativos (Barbosa-Filho et al., 2005).

Extratos vegetais secos por aspersão têm sido utilizados como produtos finais e intermediários na obtenção de diferentes formas farmacêuticas (Vasconcelos et al., 2005). Apesar da forma fluida dos extratos ser a mais comumente comercializada, somente após a retirada de parte do liquido extrator é que as formulações sólidas, semi-sólidas ou líquidas podem ser preparadas. Porém, se a eliminação do solvente não for realizada corretamente pode-se provocar a perda de constituintes químicos do extrato.

A padronização de matérias primas, no caso do Symphytum officinale proposta originalmente por Saito e Oliveira (1986), representa um grande desafio, especialmente para reprodução de efeitos biológicos já que apresentam complexos requisitos para a avaliação da composição, constância, estabilidade, contagem microbiológica, etc.

Por fim, a espécie selecionada para a realização do presente trabalho figura como uma das mais utilizadas na forma tópica para o tratamento de afecções da pele de pacientes que buscam a atenção básica à saúde no Distrito Federal - Brasil. A garantia da segurança de uso e da qualidade das preparações poderá contribuir para a inserção da espécie na Relação Nacional de Medicamentos Fitoterápicos (Barbosa, 2006).

\section{MATERIAL E MÉTODOS}

\section{Material Vegetal}

O Symphytum officinale L., foi adquirido diretamente da empresa YOD Comércio de Produtos Naturais LTDA, na condição de planta seca e pulverizada, com certificado garantia.

\section{Preparação do extrato fluido}

A extração do material foi realizada de acordo com o método preconizado pela Farmacopéia Brasileira II edição (1959), em processo geral A para a obtenção de extrato fluido.

\section{Análise preliminar das características de secagem do extrato fluido}

As características de secagem do extrato fluido de Symphytum officinale puro e adicionado com diferentes concentrações do adjuvante de secagem escolhido (hidroxietilcelulose - HEC), foram avaliadas pelo espalhamento de $5 \mathrm{~g}$ de cada amostra em uma placa de vidro. Em seguida a placa foi submetida à secagem em estufa de ar circulante por 1 hora a $95^{\circ} \mathrm{C}$.

A Adição de HEC no extrato se deu nas concentrações de $0,5,0,75$ e $1,5 \%(\mathrm{p} / \mathrm{v})$ sob constante agitação em agitador magnético a $400 \mathrm{rpm}$. A formulação contendo $1,5 \%$ de HEC foi preparada pela adição do adjuvante após a diluição do extrato com água destilada na proporção de 1:1.

\section{Secagem da formulação selecionada pelo método de spray drying}

Para a etapa de secagem do extrato seco de $S$. officinale foi empregado um spray dryier. A atomização do material dentro da câmara foi realizada pelo emprego de uma bomba peristáltica e de um bico atomizador tipo duplo fluido com diâmetro de saída de $2 \mathrm{~mm}$. As condições operacionais empregadas nesse trabalho estão descritas na Tabela 1 .

A vazão do ar de secagem empregada durante o processamento foi calculada através da utilização de um tubo de Pitot acoplado a um manômetro de água, através da equação:

$$
V o=A \sqrt{\frac{\left(\rho_{m}-\rho\right) \Delta h \cdot g}{\rho}}
$$

Tabela 1. Condições operatórias utilizadas na secagem por nebulização do extrato fluido de Symphytum officinale

\begin{tabular}{lc}
\hline Parâmetro operacional & Nível empregado \\
\hline Temperatura de saída $\left({ }^{\circ} \mathrm{C}\right)$ & 100,00 \\
\hline Vazão do ar de atomização (L/minuto) & 04,00 \\
\hline Vazão do ar de secagem $\left(\mathrm{m}^{3} /\right.$ hora $)$ & 27,83 \\
\hline Vazão de alimentação do extrato (mL/minuto) & 04,00 \\
\hline
\end{tabular}

Obtenção dos perfis termogravimétrico, espectroscópico e cromatográfico

\section{Perfil termogravimétrico}

O extrato fluido seco por nebulização de $S$. officinale foram analisado e as curvas termogravimétricas foram obtidas em um analisador térmico Shymadzu nas seguintes condições: Razão de aquecimento - $5^{\circ} \mathrm{C} / \mathrm{min}$.; Peso da amostra - aproximadamente $8 \mathrm{mg}$; Atmosfera - nitrogênio; Fluxo - 25,00 mL/min; Material da célula - platina. 


\section{Perfil espectroscópico}

Os extratos fluido liofilizado e seco por nebulização de $S$. officinale foram analisados e os espectros foram obtidos com o uso de um aparelho de infravermelho com transformador de Fourrier (FTIR) da marca Nicolet, modelo Proteje 460. As leituras foram realizadas em comprimento de onda na faixa de 400 a $4000 \mathrm{~cm}^{-1}$. Quantidades apropriadas da droga vegetal foram comprimidas com $\mathrm{KBr}$.

\section{Perfil cromatográfico}

Os perfis cromatográficos dos extratos fluido liofilizado e seco por nebulização foram obtidos em cromatógrafo da Marca Varian Pro-star, detetor UVvisível, com operação em $218 \mathrm{~nm}$, injeção manual em um loop de $20 \mu \mathrm{L}$, sobre uma coluna analítica Merck ${ }^{\circledR}$ ODS $(4,6 \mathrm{~mm} \times 250 \mathrm{~mm})$. O processo de desenvolvimento foi realizado utilizando como fase móvel tampão fosfato de sódio $10 \mathrm{mM}, \mathrm{pH} 4,0$, com um fluxo de $0,5 \mathrm{~mL} / \mathrm{m}^{-1}$.

\section{RESULTADOS E DISCUSSÃO}

A análise do teor de etanol no extrato fluido de $S$. officinale por picnometria mostrou um teor médio de $26,83 \%(\mathrm{v} / \mathrm{v}) \pm 1,04$.

A Figura 1 mostra os produtos da secagem do extrato fluido, com e sem a adição do adjuvante de secagem escolhido, a hidroxietilcelulose. O rendimento médio da operação de secagem por spray drying foi de $20 \%$.

A determinação de etanol nas amostras destiladas do extrato fluido de $S$. officinale, além da importância para a caracterização da preparação, visa também garantir condições seguras durante a operação de secagem do material.

Na Figura 1A observa-se o aspecto de "melaço" apresentado pelo extrato seco sem o acréscimo de adjuvantes de secagem. A elevada viscosidade do material se deve provavelmente à presença de uma quantidade considerável de açúcares de baixo peso molecular na preparação o que constitui característica comum nesse tipo de preparação. As Figuras 1B, 1C e 1D mostram o extrato fluido de $S$. officinale seco com a adição de hidroxietilcelulose em concentrações de $0,5,1,0$ e $1,5 \%$, respectivamente. Nota-se claramente que, com o aumento da concentração do adjuvante de secagem há uma diminuição da viscosidade do material sem que, no entanto, se observe o desprendimento do material da superfície do vidro. Esse é, provavelmente, efeito do polímero sobre a temperatura de transição vítrea da mistura dos constituintes químicos do extrato (em especial açúcares). A formulação contendo 1,5 \% de HEC (Figura 1D), apresenta aspecto visual mais fosco e uma reduzida viscosidade em relação às outras formulações, e por isso foi escolhida para a secagem em spray drying, possibilitando uma melhor recuperação do produto
A

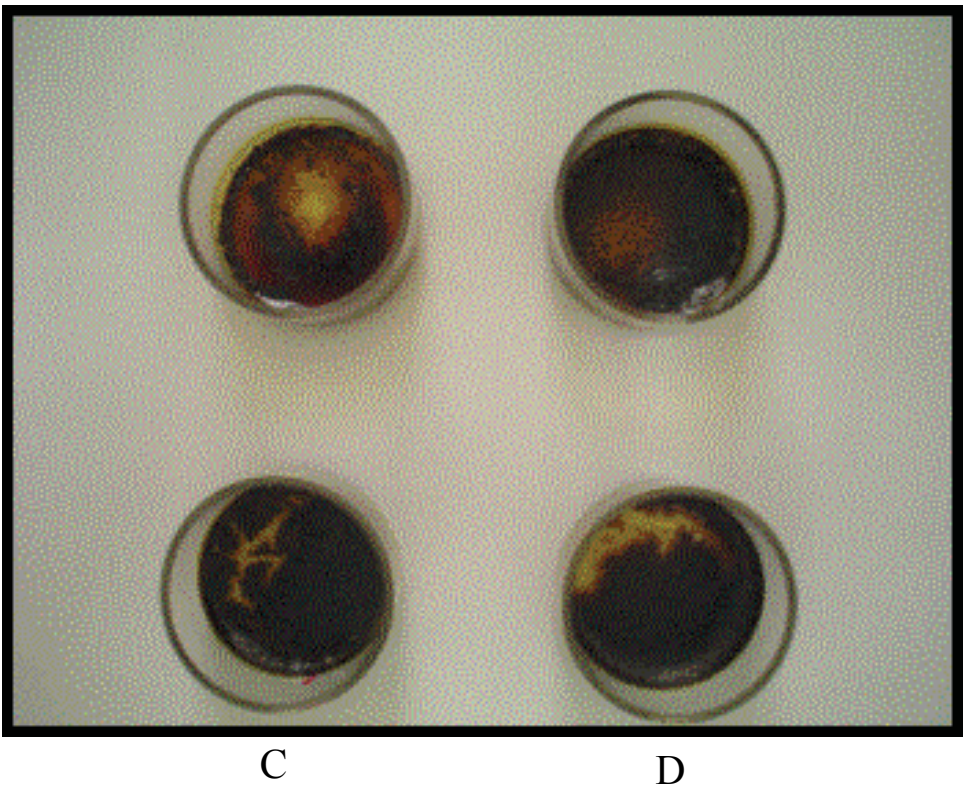

Figura 1. Secagem em estufa do extrato fluido de Symphytum officinale (A) extrato sem adição de adjuvantes; (B) extrato com HEC a $0,5 \%$; (C) extrato com HEC a 1,0 \%; (D) extrato com HEC a 1,5\%. 


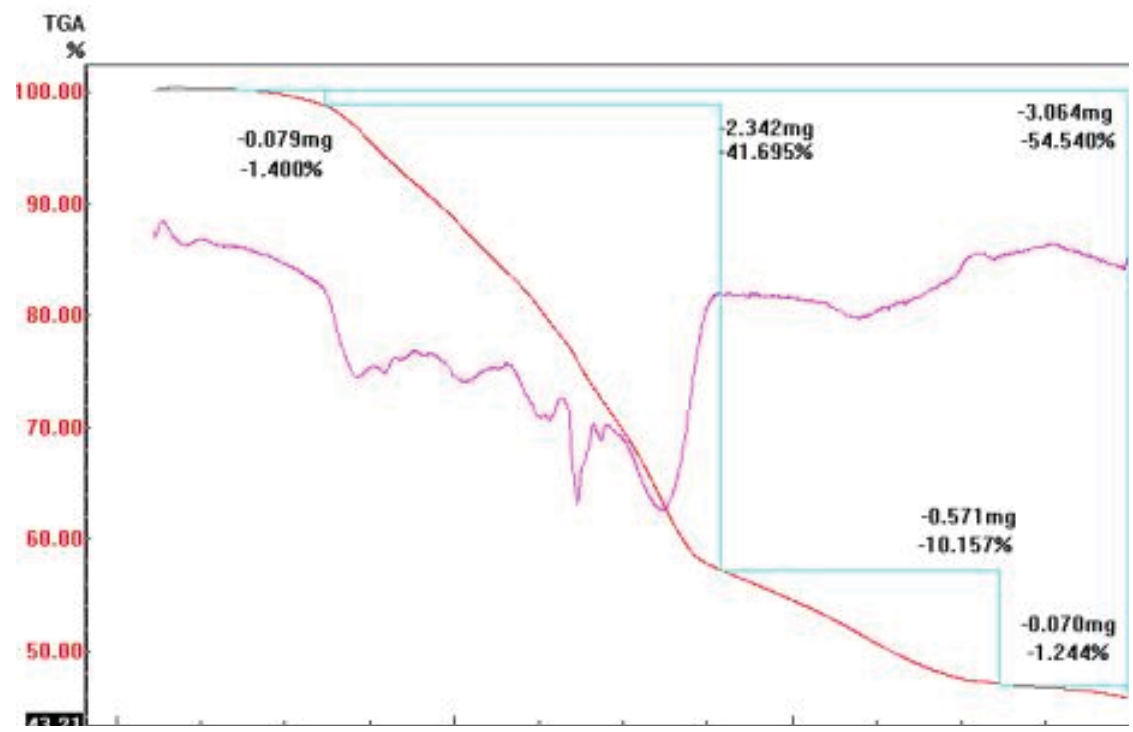

Figura 2. Curva TG do extrato fluido liofilizado de Symphytum officinale

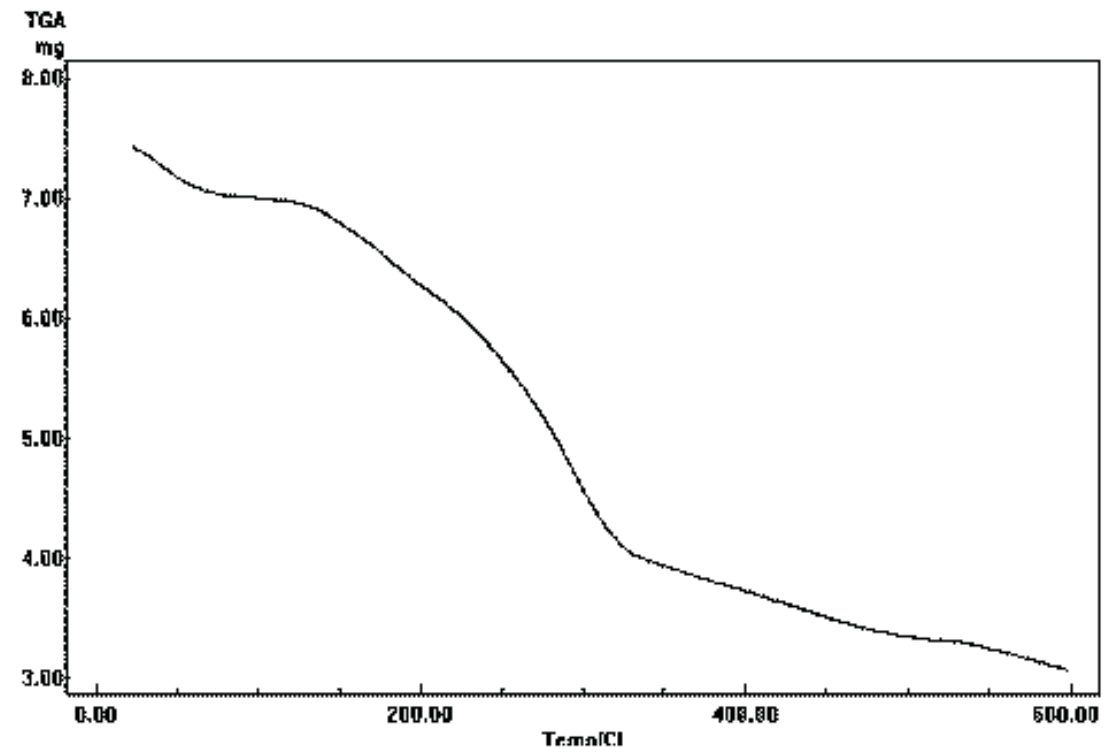

Figura 3. Curva TG do extrato seco por nebulização de Symphytum officinale.

durante seu processamento.

Dessa forma, e direcionado pelas características desejadas para o produto final, optou-se por não adicionar quantidades superiores do referido adjuvante ou mesmo qualquer quantidade de outro adjuvante de secagem à preparação.

A otimização dos parâmetros de secagem como temperaturas de entrada e saída, velocidade de fluxo de alimentação, concentração e tipo de adjuvante tecnológico, assim como os teores de resíduo seco do extrato fluido a nebulizar são fatores indispensáveis para obtenção de extratos secos com melhores características físico-químicas e aumento do rendimento da operação (Gaudy et al., 1991; Paula et al., 1998, Vasconcelos et al., 2005).

Os cálculos referentes ao teor de etanol na preparação vegetal foram empregados juntamente com o valor encontrado para a vazão de ar no spray drier (Tabela 1), no intuito de determinar uma vazão de extrato segura para a secagem do extrato fluido hidroetanólico de S. officinale. Segundo List \& Schmidt (1989), a faixa de inflamabilidade do etanol no ar sob pressão atmosférica é de 3,0 a $15 \%$. Se a concentração do referido solvente estiver dentro dessa faixa durante a secagem do material, a operação é revestida de um alto risco de explosão. Com base nessa assertiva programou-se uma vazão de $4,0 \mathrm{~mL}$ de extrato por minuto (Tabela 1), o que garantiu a manutenção de uma concentração de etanol dentro 


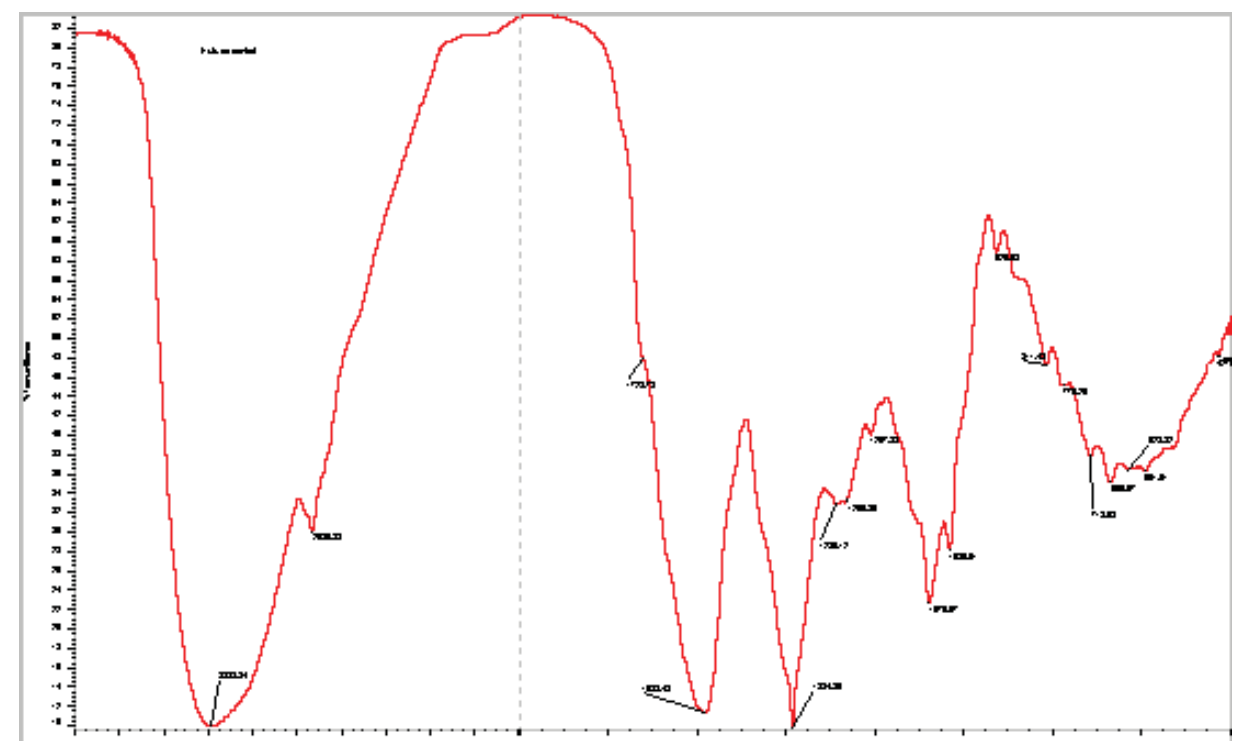

Figura 4. Espectro na região do infravermelho do extrato fluido liofilizado de Symphytum officinale.

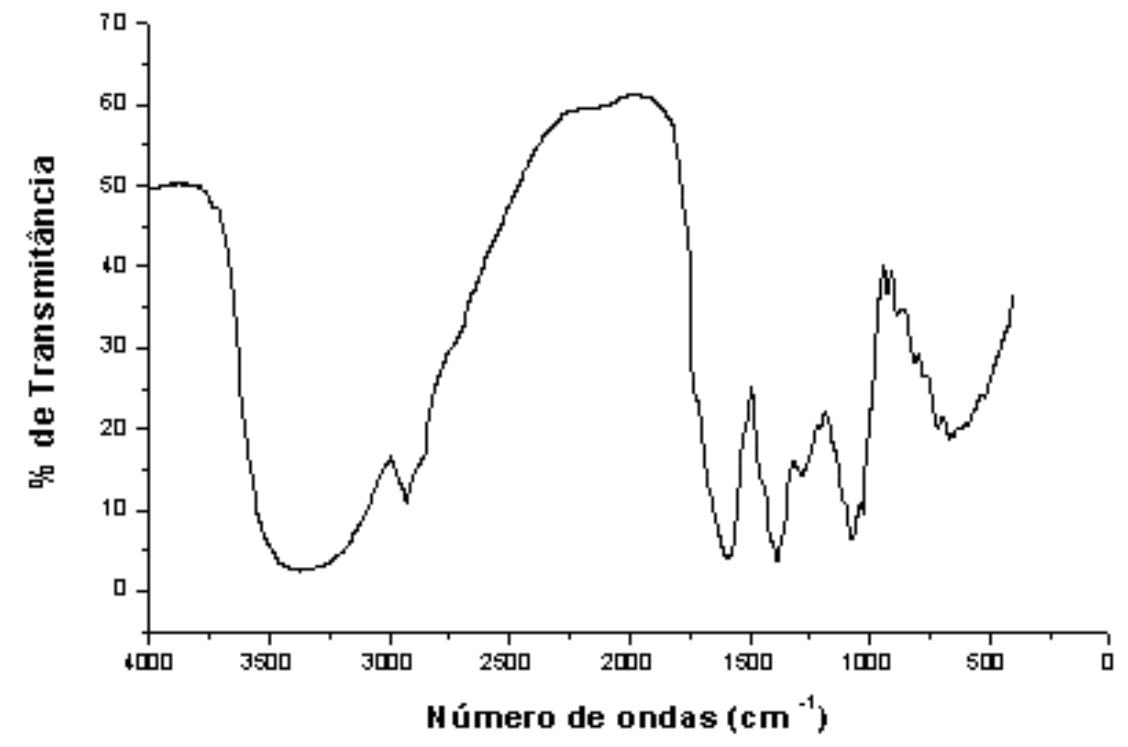

Figura 5. Espectro IV do extrato seco por nebulização de Symphytum officinale.

da câmara de secagem sempre muito abaixo do limite inferior de inflamabilidade do solvente (Kirk, 1994).

De acordo com a curva termogravimétrica do extrato fluido liofilizado observa-se até $145{ }^{\circ} \mathrm{C}$ uma perda de massa de $1,400 \%$, no intervalo de $150{ }^{\circ} \mathrm{C}$ a 350 ${ }^{\circ} \mathrm{C}$ ocorre uma perda acumulada de $41,695 \%$, que atinge $54,540 \%$ até $600{ }^{\circ} \mathrm{C}$ (Figura 2).

$\mathrm{O}$ resultado obtido no ensaio gravimétrico de perda por dessecação para o extrato fluido de $S$. officinale no valor de $8,83 \%$ está entre os valores observados pelas curvas TGA no intervalo de temperatura de interesse, mostrando que a termogravimetria pode fornecer uma estimativa do conteúdo de água residual presente no material após seu preparo.

A decomposição térmica do extrato seco se inicia por volta de $120^{\circ} \mathrm{C}$ com um percentual de perda de massa de $58 \%$ ao final a uma temperatura de $600{ }^{\circ} \mathrm{C}$. Observouse também uma série de eventos na região de $120{ }^{\circ} \mathrm{C}$ a $320{ }^{\circ} \mathrm{C}$ que podem ser atribuídos a decomposição de matéria orgânica (Figura 3).

Os espectros dos extratos fluido e seco (Figuras 4 e 5) apresentaram fortes absorções na região de 3500$3200 \mathrm{~cm}^{-1}$ sugerindo a presença de hidroxilas. Absorções na região de $1700-1600 \mathrm{~cm}^{-1}$ sugerem também a presença 


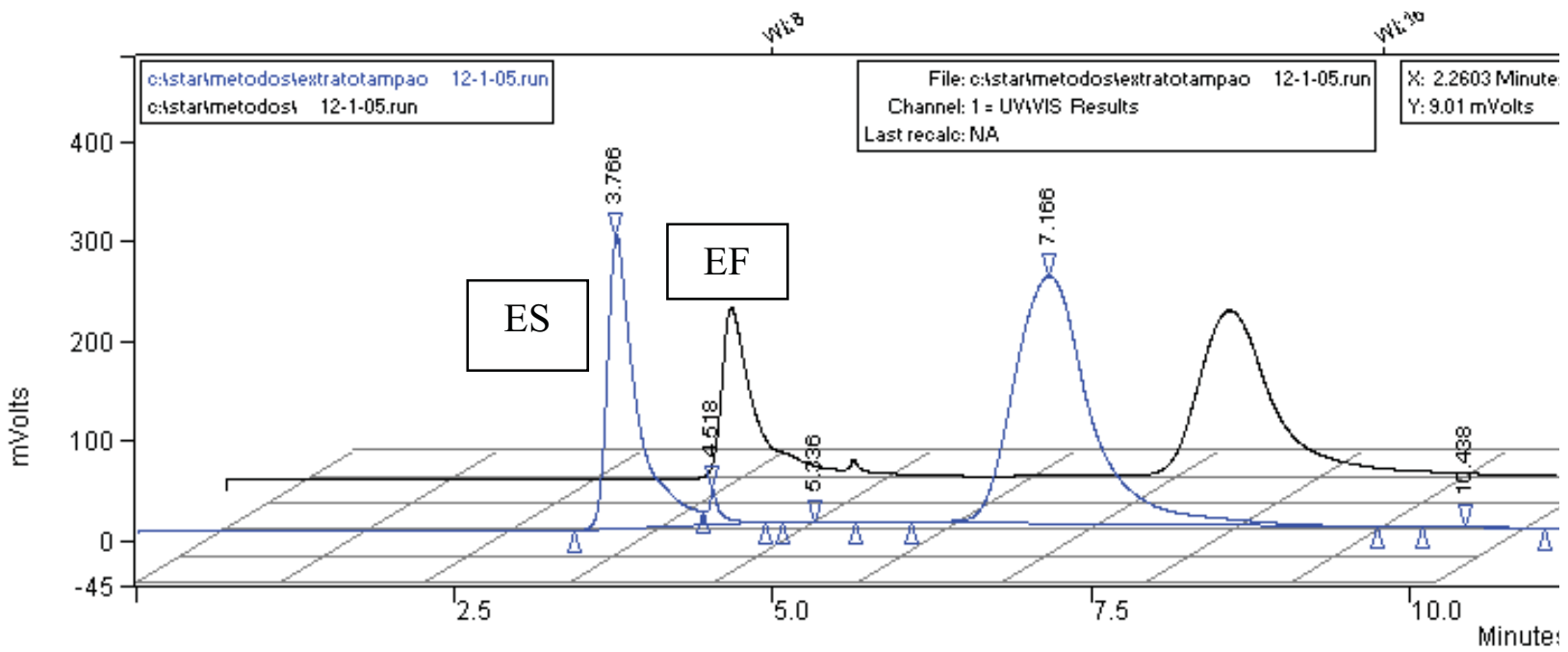

Figura 6. Perfis cromatográficos obtidos dos extratos fluido(EF) e seco(ES) de Symphytum officinale por cromatografia líquida de alta eficiência.

de carbonilas. A faixa compreendida de 1100 - 1331 $\mathrm{cm}^{-1}$ (éteres), sugerem a presença de uma ampla classe de metabólitos secundários (flavonóides, cumarinas, antraquinonas, alcalóides quinolínicos e quinolônicos e outros fenil propanóides).

Conforme cromatograma apresentado na Figura 6, podemos observar que os extratos fluido e seco apresentaram um perfil químico semelhantes sugerindo que provavelmente o procedimento de secagem não tenha interferido na integridade de seus constituintes, entre eles a alantoina.

Nos extratos fluido e seco de $S$. officinale analisados por cromatografia líquida de alta eficiência detectou-se a alantoína, com tempo de retenção de 4,518 min. (Figura 6). Nas condições analíticas empregadas, a substância pura apresentou um tempo de retenção em torno de 4,32 $\mathrm{min}$. Conforme demonstrou o valor da regressão da curva obtida para alantoína, existe linearidade no intervalo de concentração analisado, permitindo assim, o doseamento desta substância por CLAE.

\section{CONCLUSÃO}

O procedimento de secagem do extrato fluido de Symphytum officinale por nebulização mostrou que a utilização de hidroxietilcelulose como adjuvante de secagem, na concentração de $1,5 \%$, propicia uma melhor recuperação do produto seco durante seu processamento. Os perfis térmicos, espectrais por ultravioleta e cromatográfico por cromatografia líquida de alta eficiência apresentaram-se semelhantes para o extrato fluido liofilizado e para o seco por nebulização sugerindo que o procedimento de secagem não tenha interferido na integridade de seus constituintes, entre eles a alantoina.

\section{AGRADECIMENTOS}

Ao Centro Universitário do Pará - CESUPA, pelo auxílio na forma de bolsa concedida.

\section{REFERÊNCIAS}

Alzugaray D, Alzugaray K 1988. Enciclopédia de Plantas Brasileiras, São Paulo: Editora três.

Barbosa WLR 2006. Comunicação pessoal.

Barbosa-Filho JM, Vasconcelos THC, Alencar AA, Batista LM, Oliveira RAG, Guedes DN, Falcão HS, Moura MD, Diniz MFFM, Modesto-Filho J 2005. Plants and their active constituents from South, Central, and North America with hypoglycemic activity. Rev Bras Farmacogn 15: 392-413.

Brasil 2004. Ministério da Saúde, Agencia Nacional de Vigilância Sanitária. Resolução Diretora Colegiada ${ }^{\circ}$ 48 de 16 de março de 2004. Aprova o regulamento técnico sobre registro de medicamentos fitoterápicos. Diário Oficial da Republica Federativa do Brasil, Brasília/DF.

Chiryat'Ev EA, Rusakova OA 1994. Species of the Siberian flora as sources of direct action antcoagulants. Rastitel'nye Resursy 30: 21-28.

Duarte FR 1984. Influência de dois tipos de solos sobre o teor total de alcalóides do confrei. Dissertação de Mestrado, UNESP, Piracicaba.

Estrela E 1995. Tratado de Cooperaçion Amazonica - Secretaria Protempore, Plantas medicinales Amazônicas: Realidad y Perspectivas, Lima: TCA.

Falcão HS, Lima IO, Santos VL, Dantas HF, Diniz MFFM, Barbosa-Filho JM, Batista LM 2005. Review of the plants with anti-inflammatory activity studied in Brazil. Rev Bras Farmacogn 15: 381-391.

Farmacopéia Brasileira 1959. 2.ed. São Paulo: Indústria Gráfica Siqueira.

Gaudy D, Puech A, Jacob M 1991. Rôle de l'adjuvant dans l'optimization de la production d'un extrait sec vegetal nébulisé: "cas de l'extrait de Noix vomique". Acta Pharm Helv 66: 5-10.

Kirk O 1994. Encyclopedia of Chemical Technology. Vol. 9, 
pp.812, 4 edição: John Wiley and Sons.

List PH, Schmidt, PC 1989. Phytopharmaceutical Technology. CRC Press, Florida.

Matos FJA 1994. Farmácias vivas: sistema de utilização de plantas medicinais projetado para pequenas comunidades, 2. Ed., Fortaleza: UFC.

Morrison EY, West ME 1982. A preliminary study of the effects of some West Indian medicinal plants on blood sugar levels in the dog. West Indian Med J 31: 194-197.

Paula IC, Ortega GG, Bassani VL, Petrovick PR 1998. Development of ointment formulations prepared with Achyrocline satureoides spray-dried extracts. Drug Dev Ind Pharm 24: 235-241.

Saito ML, Oliveira F 1986. Confrei - virtudes e problemas. Rev Bras Farmacogn 1: 74-85.

Sener B, Atta-Ur R 1994. Recent results in the search of bioactive compounds from turkish medicinal plants. Pure Appl Chem 66: 2295-2288.

Soares IC, Nicoletti MA, Conciglieri VO 1986. Incorporação de extrato f;luído de Symphytum officinale L. em cremes evanescentes. Rev Bras farmacogn 1(Supl.): 42.

Toledo ACO, Duarte MR, Nakashima T 2003. Análise farmacognóstica da droga e do extrato flúido das folhas de Symphytum officinale L. (Boraginaceae). Rev Bras Farmacogn 13(Supl. 2): 1-2.

Toledo ACO, Duarte MR, Nakashima T 2006. Caracterização morfoanatômica de raízes e rizomas de Symphytum officinale L. (Boraginacea). Rev Bras Farmacogn 16: 185-191.

Vasconcelos EAF, Medeiros MGF, Raffin FN, Moura TFAL 2005. Influência da temperatura de secagem e da concentração de Aerosil ${ }^{\mathbb{B}} 200$ nas características dos extratos secos por aspersão da Schinus terebinthifolius Raddi (Anacardiaceae), Rev Bras Farmacogn 15: 243-249. 